\title{
Feira de Ciências da Cantu na UFFS: comunicação científica para a comunidade regional, escolar e acadêmica
}

\author{
Feira de Ciências da Cantu na UFFS: scientific communication for the \\ regional, school and academic community
}
Feira de Ciências da Cantu na UFFS: comunicación científica para la comunidad regional, escolar y académica

\author{
Vivian Machado de Menezes (demenezes.vivian@gmail.com) \\ Universidade Federal da Fronteira Sul - UFFS \\ Vanderleia Dezingrini (vanderleia@gmail.com) \\ Universidade Federal da Fronteira Sul - UFFS
}

\begin{abstract}
Resumo: Este trabalho apresenta os dados e indicadores de participação da Feira de Ciências da Cantu na UFFS, um evento proposto para proporcionar uma ferramenta de divulgação científica e interação entre a Universidade Federal da Fronteira Sul (UFFS) Campus Laranjeiras do Sul, escolas e comunidade externa da região de abrangência da Instituição. Aqui são relatados os resultados das três primeiras edições da Feira, onde foram possibilitados momentos de comunicação científica entre estudantes, professores, técnicos, pesquisadores e visitantes com temas de pesquisas nas mais diversas áreas do conhecimento. Os dados levantados apontam que o desenvolvimento destas atividades promoveu a aproximação entre os membros da comunidade acadêmica, das escolas municipais, estaduais e particulares da região e do entorno do Território Cantuquiriguaçu-PR com a UFFS - Campus Laranjeiras do Sul, fortaleceu o envolvimento de todos em atividades científicas, além de auxiliar na divulgação da Universidade e dos cursos ofertados no Campus Laranjeiras do Sul. A Feira de Ciências da Cantu na UFFS é uma oportunidade importante para que os participantes validem seus projetos de pesquisa e pratiquem suas habilidades comunicativas, socializando seus trabalhos com diferentes públicos da comunidade escolar, acadêmica e regional.
\end{abstract}

Palavras-chave: divulgação científica; Escola; Universidade; pesquisa; projeto; alfabetização científica.

Abstract: This work presents the data and indicators of participation of the Feira de Ciências da Cantu na UFFS, an event proposed to provide a dissemination and interaction tool between the Universidade Federal da Fronteira Sul (UFFS) - Campus Laranjeiras do Sul, schools and external community in the region covered by the Institution. Here the results of the first three editions of the Fair are reported, where moments of scientific communication between students, professors, technicians, researchers, and visitors with research topics in the most diverse areas of knowledge were made possible. The data collected show that the development of these activities promotes the approximation between members of the academic community, of municipal, state and private schools in the region and the surroundings of Territory 
Cantuquiriguaçu-PR with UFFS - Campus Laranjeiras do Sul, strengthened the involvement of everyone in scientific activities, as well as helping to publicize the University and the courses offered at Campus Laranjeiras do Sul. The Feira de Ciências da Cantu na UFFS is an important opportunity for participants to validate their research projects and practice their communication skills, socializing their work with different audiences in the school, academic and regional community.

Keywords: scientific dissemination; School; University; search; project; scientific literacy.

Resumen: Este artículo presenta los datos e indicadores de participación de la Feira de Ciências da Cantu na UFFS, un evento propuesto para proveer una herramienta de divulgación científica e interacción entre la Universidade Federal da Fronteira Sul (UFFS) - Campus Laranjeiras do Sul, las escuelas y la comunidad externa de la región de cobertura de la Institución. Aquí se reportan los resultados de las tres primeras ediciones de la Feria, donde se posibilitaron momentos de comunicación científica entre estudiantes, profesores, técnicos, investigadores y visitantes con temas de investigación en las más diversas áreas del conocimiento. Los datos recolectados muestran que el desarrollo de estas actividades promovió la aproximación entre miembros de la comunidad académica, escuelas municipales, estatales y privadas de la región y alrededor del Territorio Cantuquiriguaçu-PR con la UFFS - Campus Laranjeiras do Sul, fortaleció la participación de todos en actividades científicas, además de ayudar a dar a conocer la Universidad y los cursos que se ofrecen en el Campus Laranjeiras do Sul. La Feira de Ciências da Cantu na UFFS es una oportunidad importante para que los participantes validen sus proyectos de investigación y practiquen sus habilidades comunicativas, socializando sus trabajos con diferentes audiencias en la comunidad escolar, académica y regional.

Palabras-clave: divulgación científica; Escuela; Universidad; investigación; proyecto; alfabetización científica.

\section{INTRODUÇÃO}

A Universidade Federal da Fronteira Sul (UFFS) é uma instituição de ensino superior pública e popular, criada no ano de 2009, pela Lei $\mathrm{N}^{\circ} 12.029$, de 15 de setembro. A UFFS possui seis campi situados na Mesorregião Grande Fronteira do Mercosul, entre eles está o Campus localizado no município paranaense de Laranjeiras do Sul.

Conforme o Art. $6^{\circ}$ do Estatuto da UFFS, entre os princípios da Instituição estão a "indissociabilidade entre ensino, pesquisa e extensão; diálogo permanente com a comunidade regional da abrangência da Instituição". Além disso, uma das finalidades da Instituição, elencadas no Art. $7^{\circ}$ do Estatuto, é “a extensão universitária, aberta à 
participação da população, visando à produção conjunta de avanços, conquistas e benefícios resultantes da criação cultural e artística e da pesquisa científica e tecnológica" (UNIVERSIDADE FEDERAL DA FRONTEIRA SUL, 2015, p. 6-7).

Complementando o citado acima, o Regimento Geral da UFFS prevê no Art. $68^{\circ}$ que "a extensão é uma atividade fim da Universidade, de caráter educativo, cultural e científico, articulada de forma indissociada com o ensino e a pesquisa, e visa à relação transformadora entre universidade e sociedade" (UNIVERSIDADE FEDERAL DA FRONTEIRA SUL, 2016, p. 24).

Nessa perspectiva, Trevisol, Cordeiro e Hass (2011) destacam que as ações de extensão promovem e fomentam o relacionamento entre a Universidade e a sociedade, desenvolvendo projetos comprometidos com a inclusão social, com a produção e a disseminação do conhecimento para a melhoria da qualidade de vida das pessoas, estimulando o diálogo de saberes entre a Universidade e a comunidade, tornando democrático o acesso da população aos conhecimentos acadêmicos, estimulando a participação da comunidade e possibilitando intercâmbio entre instituições, organizações e movimentos organizados da sociedade.

A partir do exposto, entende-se que a realização de eventos que contemplam e possibilitam a participação da comunidade regional e a interação com a Universidade atendem aos objetivos e finalidades da Instituição, oportunizando a disseminação de conhecimentos e a divulgação científica, além de possibilitar o estreitamento e a consolidação do relacionamento da Instituição com a comunidade, promovendo o reconhecimento e fortalecimento da imagem institucional.

Dentre as possibilidades de eventos acadêmicos que impulsionam essa interação entre a Universidade com a comunidade local e regional estão as feiras de ciências e mostras científicas. Neste contexto surgiu a proposta para realização da Feira de Ciências da Cantu na UFFS, envolvendo acadêmicos, docentes e técnicos da UFFS e de outras instituições de ensino superior, além de estudantes e professores do ensino fundamental e médio, de escolas das redes municipal, estadual e particular, localizadas em Laranjeiras do Sul-PR e região.

Os conceitos sobre feira de ciências e os detalhes sobre a Feira de Ciências da Cantu na UFFS serão abordados nas seções 2 e 3, respectivamente. 


\section{AS FEIRAS DE CIÊNCIAS}

As feiras de ciências começaram a ser promovidas nas escolas brasileiras a partir dos anos 60, entretanto, nas décadas de 80 e 90 esses eventos de divulgação científica passaram a ser mais populares (SANTOS, 2012). Desde então, as feiras de ciências passaram por diversas mudanças, prezando cada vez mais pelo protagonismo estudantil e evidenciando que a pesquisa deve fazer parte do dia-a-dia dos estudantes (GALLON et al., 2019).

Nesta mesma linha, Gauterio, Guidotti e Araújo (2017, p. 2) explicam que:

As Feiras de Ciências apresentaram por muito tempo o caráter de serem voltadas, principalmente, para as disciplinas relacionadas às Ciências da Natureza, ou seja, Ciências, Biologia, Física e Química. No entanto, com o decorrer dos anos a visão se ampliou, de forma que as feiras foram reconhecidas como espaço de promoção de investigação científica, a qual perpassa pelas diversas áreas do conhecimento (GAUTERIO; GUIDOTTI; ARAÚJO, 2017, p. 2).

A definição de feira de ciências é apresentada no documento elaborado pelo Ministério de Educação (BRASIL, 2006), que descreve:

Feiras de ciências são eventos sociais, científicos e culturais realizados nas escolas ou na comunidade com a intenção de, durante a apresentação dos estudantes, oportunizar um diálogo com os visitantes, constituindo-se na oportunidade de discussão sobre os conhecimentos, metodologias de pesquisa e criatividade dos alunos em todos os aspectos referentes à exibição de trabalhos (MANCUSO, 2006 apud BRASIL, 2006, p. 20).

Segundo Gauterio, Guidotti e Araújo (2017, p. 3) "a Feira de Ciências é um momento, onde é possível envolver o aluno em uma investigação científica, propiciando um conjunto de experiências interdisciplinares, além de integrar o corpo docente em atividades diferenciadas". Para os autores, as feiras de ciências são consideradas espaços não-formais, que fomentam a socialização e a divulgação científica e que podem ser consideradas como eventos nos quais estudantes submetem seus trabalhos aos olhares críticos e construtivos de avaliadores (GAUTERIO; GUIDOTTI; ARAÚJO, 2017, p. 3).

Sousa et al. (2016) relatam que as feiras de ciências favorecem a troca de experiências e a socialização dos conhecimentos. Para os autores, "as feiras produzem 
resultados positivos para toda a comunidade escolar, sobretudo no que diz respeito ao desenvolvimento da criticidade e criatividade" (SOUSA et al., 2016, p. 4).

Neste sentido, pode-se dizer que as feiras de ciências são eventos que possibilitam aos estudantes divulgar conceitos estudados, expor ideias, praticar suas habilidades comunicativas e, além disso, permitem a interação e a divulgação científica, despertando nos estudantes a criatividade e o interesse pela ciência.

Para Santos (2012), as feiras de ciências se constituem como um importante espaço pedagógico possibilitando aos alunos o desenvolvimento de diversas habilidades, uma vez que participam ativamente do processo que resulta na construção de conhecimentos, que muitas vezes não ocorrem no espaço formal de sala de aula. Desta forma, compreende-se a importância de fomentar a realização e a participação de estudantes, docentes e demais membros da comunidade escolar e universitária em feiras de ciências, tendo em vista que esses eventos propiciam a construção de conhecimentos, a comunicação científica e possibilitam diversas experiências e momentos formativos para além daquilo que é vivenciado em sala de aula.

\section{A FEIRA DE CIÊNCIAS DA CANTU NA UFFS}

A Feira de Ciências da Cantu na UFFS foi concebida visando ampliar as possibilidades de elaboração e desenvolvimento de projetos de pesquisa junto às escolas e à Universidade Federal da Fronteira Sul, em razão da necessidade de construir novos conhecimentos, contribuindo com a formação de sujeitos comprometidos com a transformação social. Desta forma, a Universidade cumpre com o seu papel de estreitar os laços e articular o conhecimento construído nos espaços de docência e pesquisa com as escolas e com a comunidade externa.

As três edições da Feira de Ciências da Cantu na UFFS foram realizadas no bloco A do Campus Laranjeiras do Sul, da Universidade Federal da Fronteira Sul, no Paraná. A primeira edição aconteceu no dia 29 de novembro de 2017, a segunda ocorreu no dia 17 de outubro de 2018 e a terceira em 05 de novembro de 2019. A quarta edição que estava prevista para 2020 não ocorreu em virtude da pandemia da COVID-19. Os projetos dos eventos foram submetidos à análise da Coordenação Adjunta de Extensão e 
Pesquisa do Campus, por meio da plataforma PRISMA de projetos da UFFS, na modalidade demanda espontânea de ação de extensão.

O projeto teve como objetivo geral promover a interação entre a UFFS, escolas e comunidade externa, contemplando os três pilares da Universidade: Ensino, Pesquisa e Extensão.

Os objetivos específicos consistiam em:

- Divulgar a Universidade e os cursos ofertados no Campus;

- $\quad$ Envolver estudantes, professores e técnicos em atividades científicas;

- $\quad$ Promover a inovação científico-tecnológica;

- Despertar vocações e revelar capacidades, criatividade e habilidades científicas;

- Promover o aprendizado por meio da experiência como forma de estimular o interesse pela busca de conhecimento;

- Criar um espaço para a socialização das atividades de pesquisa por membros da comunidade acadêmica e escolas da região da Cantuquiriguaçu;

- $\quad$ Fortalecer o vínculo entre a UFFS e a comunidade local e regional.

A proposta do evento contou com a realização de uma mostra científica-cultural aberta ao público a fim de possibilitar o acesso à ciência a pessoas de todas as idades e classes sociais. A programação do evento previa a apresentação de trabalhos, almoço cultural, premiação e sorteios ao longo do evento, que começava pela manhã e terminava na tarde do mesmo dia.

A organização da Feira de Ciências da Cantu na UFFS foi estruturada pela divisão das equipes de trabalho nas seguintes comissões:

- $\quad$ Coordenação Geral;

- $\quad$ Comissão Avaliadora;

- $\quad$ Comissão de Relações Públicas e Divulgação;

- $\quad$ Comissão de Atividades Culturais; 
- $\quad$ Comissão Administrativa e de Infraestrutura;

- $\quad$ Comissão de Credenciamento;

- $\quad$ Comissão de Recepção;

- $\quad$ Comissão da Premiação;

- $\quad$ Comissão de Informações;

- $\quad$ Comissão da Feira de Cursos.

A participação na Feira de Ciências da Cantu na UFFS se deu através da inscrição de projetos/trabalhos individuais e/ou em grupo e/ou visitação à Universidade no dia do evento, sendo o público-alvo estudantes e professores das escolas da região da Cantuquiriguaçu; estudantes, professores e técnicos da UFFS e a comunidade regional.

Três meses antes das datas previstas para os eventos, a equipe de coordenação geral iniciou o trabalho de planejamento, organização e divulgação do evento e abriu as inscrições de trabalhos. Os trabalhos foram inscritos em uma das três categorias: Ensino Fundamental, Médio ou Superior. As equipes proponentes de Ensino Fundamental ou Médio deveriam ser formadas por até 4 estudantes e um professor ou técnico responsável. Já as equipes do Ensino Superior eram compostas por até cinco participantes, sendo que era opcional o acompanhamento por um docente/técnico. Durante as edições da Feira de Ciências da Cantu na UFFS foram apresentados experimentos/trabalhos dentro das seguintes áreas do conhecimento: Ciências Exatas e da Terra; Ciências Biológicas; Engenharias; Ciências da Saúde; Ciências Agrárias; Ciências Sociais; Ciências Humanas; Linguística, Letras e Artes e outras (como Tecnologias, Fotografia, Desenho e Decoração).

Dois meses após a abertura das inscrições para apresentação de trabalhos (via formulário online), as inscrições foram verificadas e homologadas para planejamento e organização da infraestrutura, e foram abertas as inscrições para os avaliadores dos trabalhos, que poderiam ser professores ou técnicos da UFFS, ou estudantes de mestrado da mesma instituição. Todas as equipes (bancas) de avaliadores eram compostas por três avaliadores, que foram distribuídos aleatoriamente nas diferentes categorias e áreas do conhecimento, mas respeitando se acaso houvesse algum conflito de interesse. As bancas que avaliaram os trabalhos pontuaram os seguintes critérios: 
apresentação, execução, explicação do fenômeno e criatividade (originalidade). Os três trabalhos com melhor classificação, dentro de cada categoria (Ensino Fundamental, Ensino Médio e Ensino Superior), foram premiados. Além disso, na segunda edição da Feira foi premiado um trabalho na categoria "Destaque do evento" e, na terceira edição foram classificados três trabalhos nesta categoria. No ato do credenciamento os visitantes receberam uma cédula de votação para que, após visitarem os trabalhos, pudessem votar no trabalho que consideraram o mais interessante do seu ponto de vista.

Foram permitidas apresentações de trabalhos experimentais demonstrativos, de verificação, de investigação e outros trabalhos de montagem, divulgação científica e/ou cunho cultural, sendo que todos foram avaliados por banca composta por três avaliadores, que atribuíram notas de 6,0 a 10,0. No ato da inscrição os grupos poderiam optar em não serem avaliados e não concorrer à premiação. Tanto a apresentação quanto a avaliação de projetos possuíam um regulamento próprio, e este foi enviado a todos os participantes credenciados, para terem ciência dos critérios e normas adotados na Feira de Ciências. Todos os participantes (organizadores, visitantes, apresentadores e avaliadores de trabalhos) que se inscreveram corretamente e compareceram ao evento receberam certificado após a realização do mesmo.

Todos os prêmios e brindes sorteados foram captados por meio de edital de Chamada Pública que tratava do recebimento de propostas de apoio econômico para a realização da Feira de Ciências da Cantu na UFFS. Através do mesmo edital foi possível disponibilizar almoço gratuito para os estudantes do Ensino Médio e Fundamental que apresentaram trabalhos na Feira, e que estiveram inscritos de acordo com o regulamento.

Ao final das edições da Feira foram realizadas discussões entre todos os organizadores para diagnosticar as dificuldades encontradas no desenvolvimento das atividades e sugerir mudanças para a melhoria dos próximos eventos.

Para o levantamento dos dados e indicadores qualitativos de participação nas três edições da Feira de Ciências da Cantu na UFFS foi realizada a análise dos dados das inscrições realizadas através de formulários online. Os dados foram tratados por meio da abordagem textual e por categorias. A partir daí foram elaborados os resultados e a organização da discussão. 


\section{DADOS E INDICADORES QUANTITATIVOS DA FEIRA DE CIÊNCIAS DA CANTU NA UFFS}

A primeira edição da Feira, realizada em 2017, contou com 86 trabalhos inscritos, de 20 instituições de ensino de seis cidades, totalizando 300 apresentadores e 300 visitantes. Na segunda edição, houve uma participação ainda maior, com 123 trabalhos inscritos e cerca de 400 apresentadores, envolvendo 27 instituições de ensino de 10 cidades da região, e, aproximadamente, 700 pessoas visitando. Já a III Feira de Ciências da Cantu na UFFS teve 175 inscrições de trabalhos, envolvendo 34 instituições de ensino e 15 municípios, totalizando, aproximadamente, 600 apresentadores de trabalhos e 500 visitantes da comunidade regional. A evolução da participação nas três edições do evento pode ser visualizada nas figuras 1 e 2 .

Conforme observado nas figuras a seguir, os números evidenciam o crescimento do evento e demonstram o engajamento da comunidade acadêmica da UFFS e das demais instituições participantes nas três edições da Feira. Além disso, pode-se dizer que, ao longo dos anos, o evento tem se consolidado como um evento científico regional, tendo em vista a participação de instituições de diversos municípios da região de Laranjeiras do Sul e entorno.

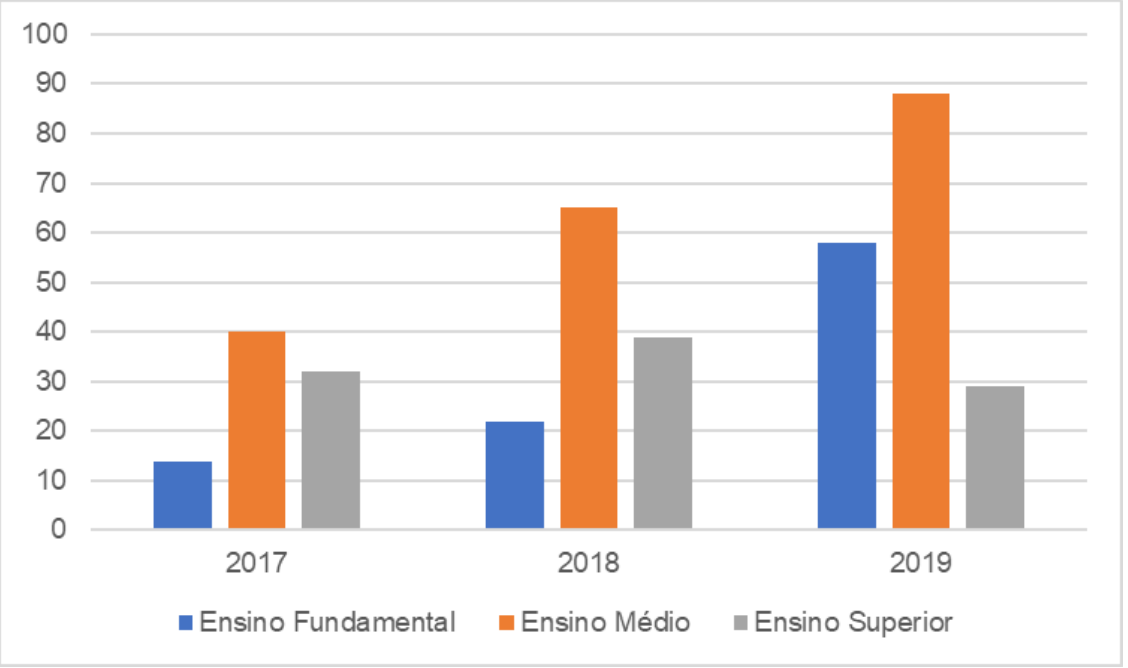

Figura 1 - Número de trabalhos inscritos por categoria em cada ano das três edições da Feira de Ciências da Cantu na UFFS. 
Embora observado na figura 1 que, no decorrer das três edições da Feira, ocorreu um crescimento do número de inscritos nas categorias Ensino Fundamental e Ensino Médio, a categoria Ensino Superior não acompanhou essa evolução. O número de inscritos na categoria Ensino Superior teve um crescimento no ano de 2018 (em relação aos inscritos em 2017), porém, em 2019 o número de trabalhos inscritos na categoria foi menor que em 2017.

$\mathrm{Na}$ figura 2 observa-se a evolução do número de envolvidos no evento (organizadores, visitantes, avaliadores, apresentadores, cidades, instituições e trabalhos), com crescimento em praticamente todas as categorias. Porém, percebe-se que o número de visitantes em 2019 foi menor que em 2018.

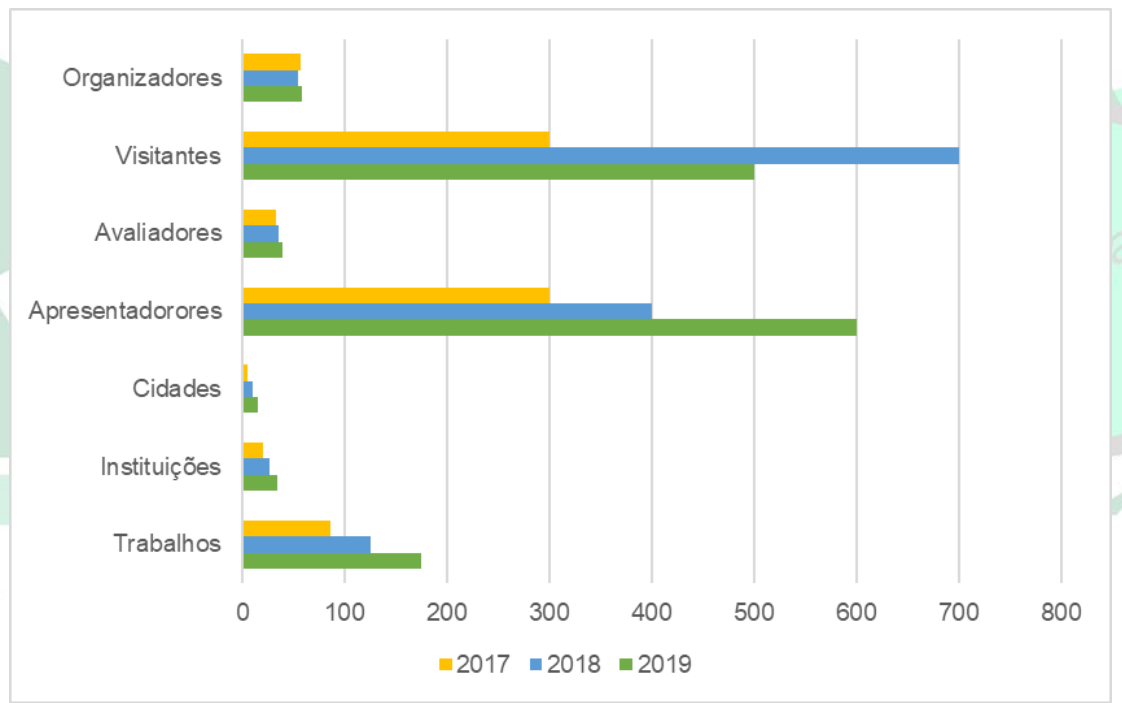
UFFS.

Figura 2 - Totais envolvidos em cada ano das três edições da Feira de Ciências da Cantu na

Para além da participação nas atividades da Feira, o evento possibilitou que diversas pessoas visitassem e tivessem um contato mais próximo com a Universidade, fortalecendo o relacionamento entre a UFFS e a comunidade local e regional e permitindo a divulgação dos cursos ofertados. As figuras 3, 4 e 5, apresentadas a seguir, são registros fotográficos das três edições da Feira. Nas imagens pode ser visualizada a movimentação interna de pessoas, em razão da participação no evento.
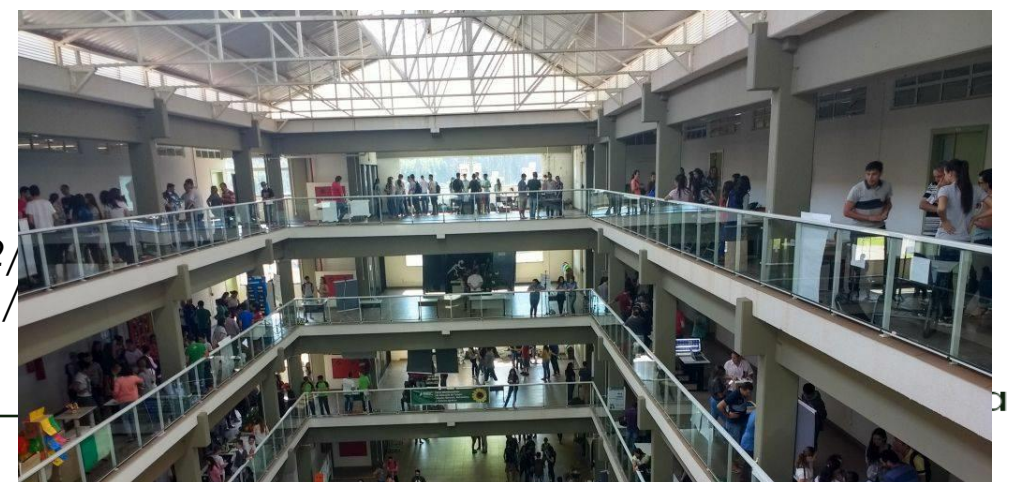
Figura 3 - Primeira edição da Feira de Ciências da Cantu na UFFS, 2017.

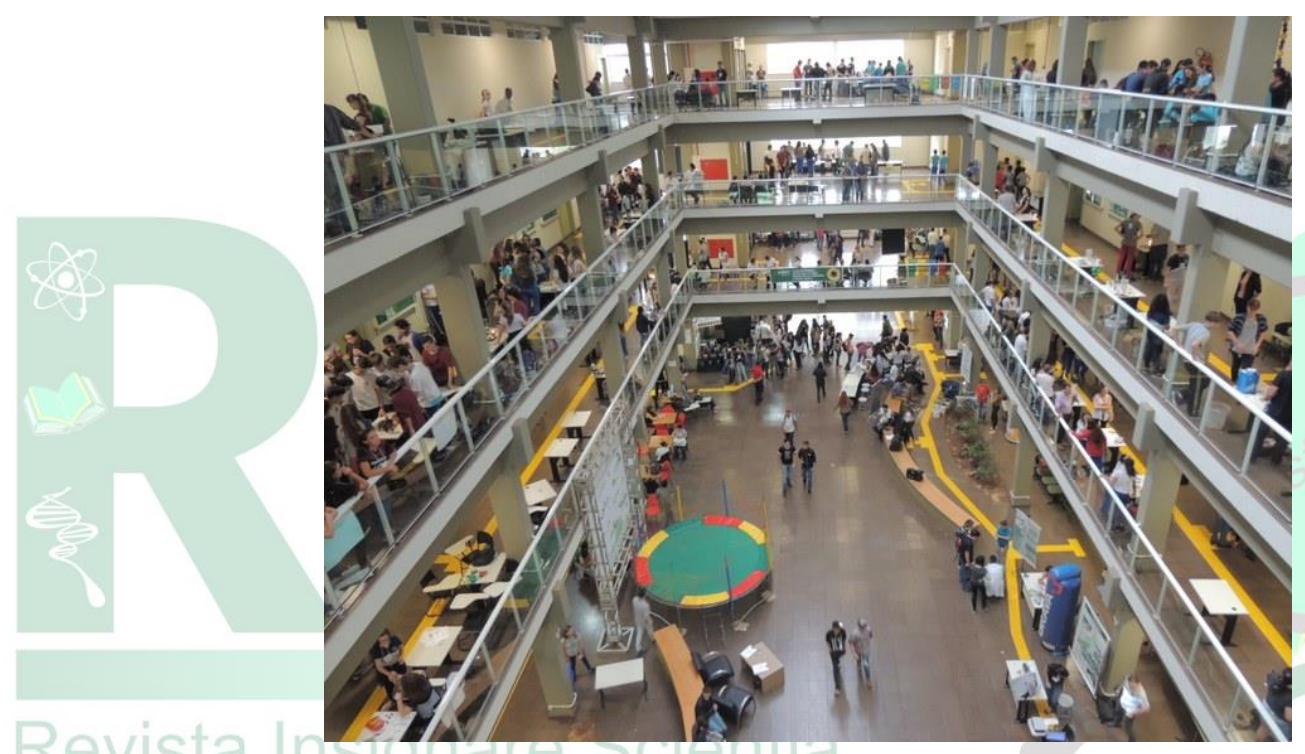

Figura 4 - Segunda edição da Feira de Ciências da Cantu na UFFS, 2018.

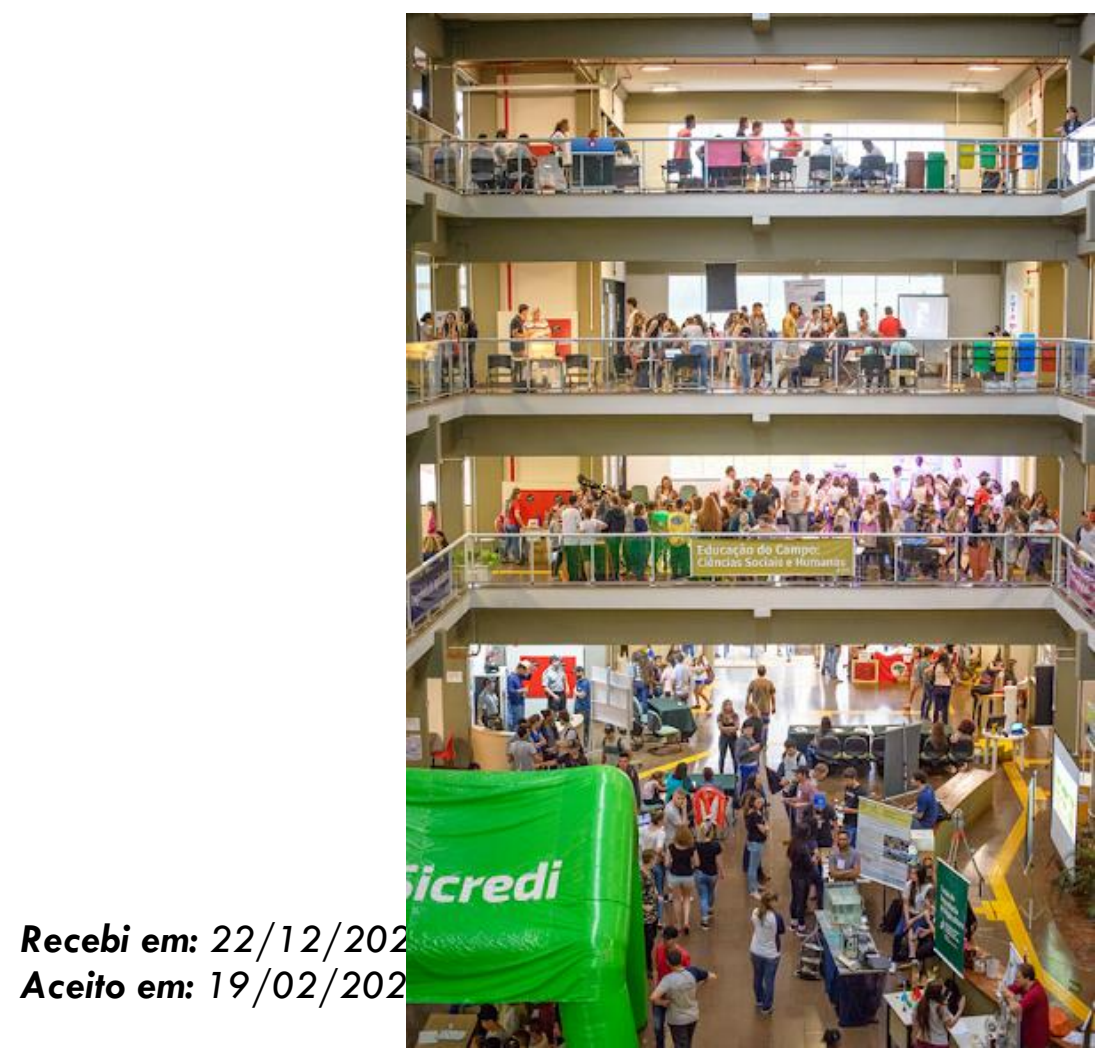


Figura 5 - Terceira edição da Feira de Ciências da Cantu na UFFS, 2019.

Pode-se observar, na figura 6, um aumento nas inscrições de trabalhos em todas as áreas do conhecimento, conforme o evento foi se consolidando ao longo dos anos. Nas três edições do evento a grande maioria dos trabalhos apresentados foram relacionados com Física, Química, Biologia, Matemática ou alguma Engenharia (classificamos como Ciências da Natureza, Exatas e Engenharias na figura 6), representando mais de $70 \%$ do total de trabalhos apresentados em todas as edições (75,58\% em 2017, 70,73\% em 2018 e 72,57\% em 2019). Pode-se observar também um percentual significativo em outra áreas do conhecimento, mostrando que as feiras e mostras científicas estão cada vez mais abrangentes e multidisciplinares, não ficando restritas a trabalhos tecnológicos ou relacionados às ciências "duras". Como muitos trabalhos possuíam caráter interdisciplinar, agrupamos algumas áreas do conhecimento no gráfico da figura 6.

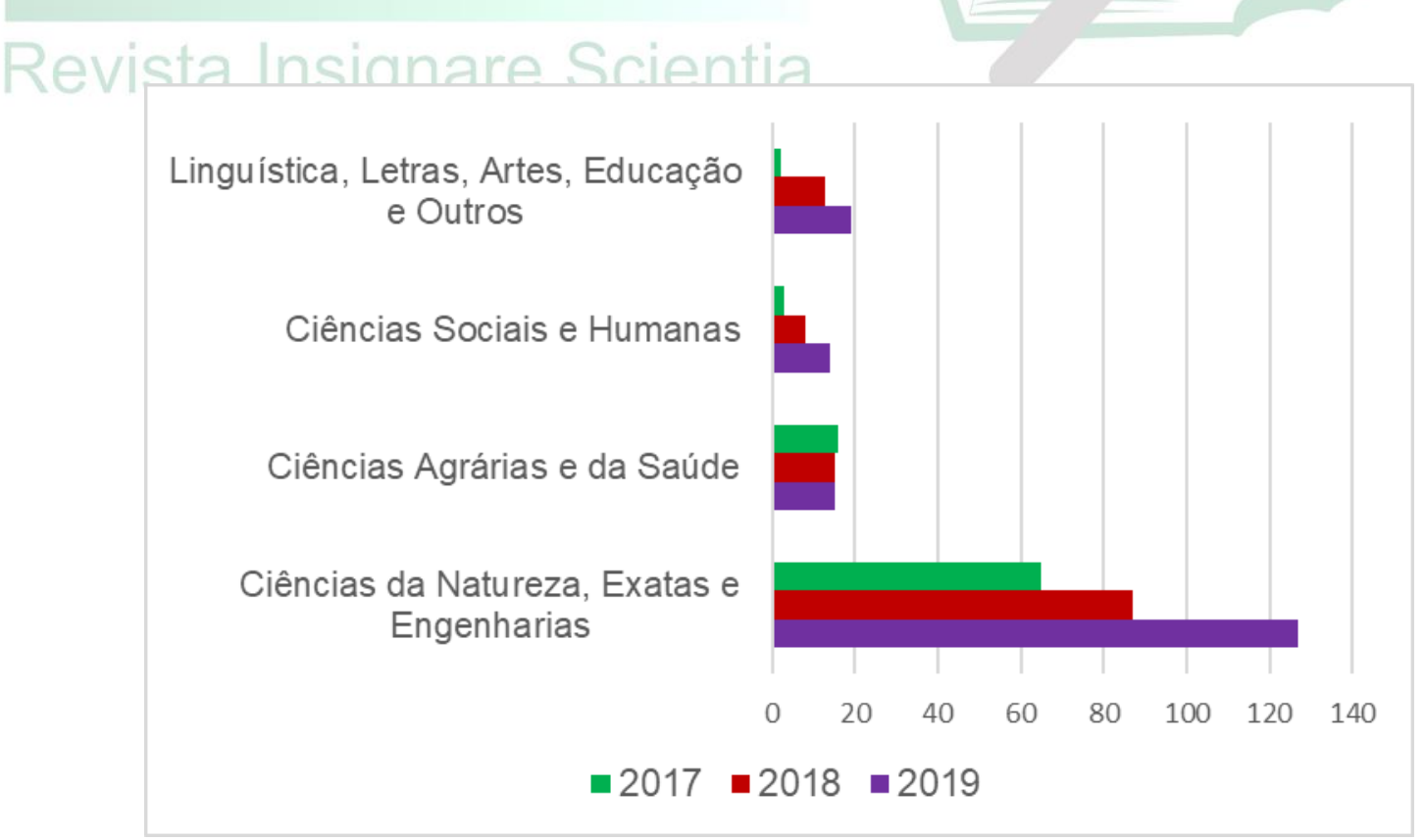

Figura 6 - Trabalhos inscritos por áreas do conhecimento na Feira de Ciências da Cantu na UFFS. 
Além da participação no evento, uma das atividades mais esperadas pelos participantes da Feira de Ciências é a premiação dos trabalhos. A classificação foi baseada na pontuação obtida na avaliação realizada pela banca e, no caso do(s) trabalho(s) destaque do evento, foi(foram) escolhido(s) mediante voto do público visitante. Ressalta-se que a categoria "Destaque do evento" foi incluída na segunda edição da Feira, premiando um trabalho e, na terceira edição foram premiados três trabalhos. A relação dos trabalhos premiados pode ser conferida nos quadros 1,2 e 3.

Como pode ser observado nos quadros 1,2 e 3 , os trabalhos premiados nas três edições do evento contemplam diversas temáticas, evidenciando o potencial da Feira de Ciências da Cantu na UFFS em promover a inovação científico-tecnológica e estimular nos estudantes o interesse pela busca de conhecimento nas mais diversas áreas. Cabe destacar que o objetivo da premiação atribuída aos apresentadores não é gerar competição, mas valorizar o trabalho realizado pelos estudantes, docentes e técnicos, incentivando para que desenvolvam experimentos científicos com qualidade técnica, que exponham trabalhos inovadores, criativos, curiosos e expositivos, e, principalmente, que promovam o aprendizado e despertem o interesse pela ciência e pela sua divulgação.

Quadro 1 - Trabalhos premiados na I Feira de Ciências da Cantu na UFFS (2017).

\begin{tabular}{|c|c|c|c|}
\hline & \multicolumn{3}{|c|}{ Título do Trabalho / Instituição de Ensino / Cidade } \\
\hline $\begin{array}{c}\text { Categoria / } \\
\text { Classificação }\end{array}$ & $1^{\circ}$ Lugar & $2^{\circ}$ Lugar & $3^{\circ}$ Lugar \\
\hline $\begin{array}{c}\text { Ensino } \\
\text { Fundamental }\end{array}$ & $\begin{array}{c}\text { Banco de Alimentos } \\
\text { / } \\
\text { Escola Estadual } \\
\text { Érico Veríssimo / } \\
\text { Laranjeiras do Sul }\end{array}$ & $\begin{array}{l}\text { Uso do Aplicativo } \\
\text { "Stop Motion" no } \\
\text { Aprendizado de } \\
\text { Embriologia / } \\
\text { Colégio Estadual } \\
\text { Professora Elenir } \\
\text { Linke / Cantagalo }\end{array}$ & $\begin{array}{l}\text { Motor Solenoide / } \\
\text { Colégio Estadual } \\
\text { Laranjeiras do Sul / } \\
\text { Laranjeiras do Sul }\end{array}$ \\
\hline $\begin{array}{l}\text { Ensino } \\
\text { Médio }\end{array}$ & $\begin{array}{l}\text { Bobina de Tesla / } \\
\text { Colégio Estadual } \\
\text { Professora Elenir } \\
\text { Linke / Cantagalo }\end{array}$ & $\begin{array}{c}\text { Protótipo de um } \\
\text { CNC (Comando } \\
\text { Numérico } \\
\text { Computadorizado) / } \\
\text { Colégio Estadual } \\
\text { Floriano Peixoto / } \\
\text { Laranjeiras do Sul }\end{array}$ & $\begin{array}{c}\text { Simulador da } \\
\text { Fisiologia do Ouvido } \\
\text { Humano / } \\
\text { Colégio Rural } \\
\text { Estadual de } \\
\text { Pinhalzinho / } \\
\text { Rio Bonito do Iguaçu }\end{array}$ \\
\hline $\begin{array}{c}\text { Ensino } \\
\text { Superior }\end{array}$ & $\begin{array}{c}\text { Construção de um } \\
\text { Foguete com Garrafa }\end{array}$ & $\begin{array}{c}\text { Vida de Inseto / } \\
\text { Universidade Federal }\end{array}$ & $\begin{array}{c}\text { Os maiores Químicos } \\
\text { do Planeta: os }\end{array}$ \\
\hline
\end{tabular}




\begin{tabular}{|c|c|c}
\hline PET / & da Fronteira Sul & microrganismos / \\
Universidade Federal & (UFFS) / & Universidade Federal \\
da Fronteira Sul & Laranjeiras do Sul & da Fronteira Sul \\
(UFFS) / & & (UFFS) / \\
Laranjeiras do Sul & & Laranjeiras do Sul \\
\hline
\end{tabular}

Conforme observado no Quadro 1, no ano de 2017, foram premiados trabalhos das áreas de Ciências da Saúde, Ciências da Natureza e Engenharias, elaborados por equipes de 6 instituições de ensino de 3 municípios. Como pode ser observado na figura 6, os trabalhos nessas áreas do conhecimento representavam a grande maioria dos trabalhos apresentados na edição de 2017.

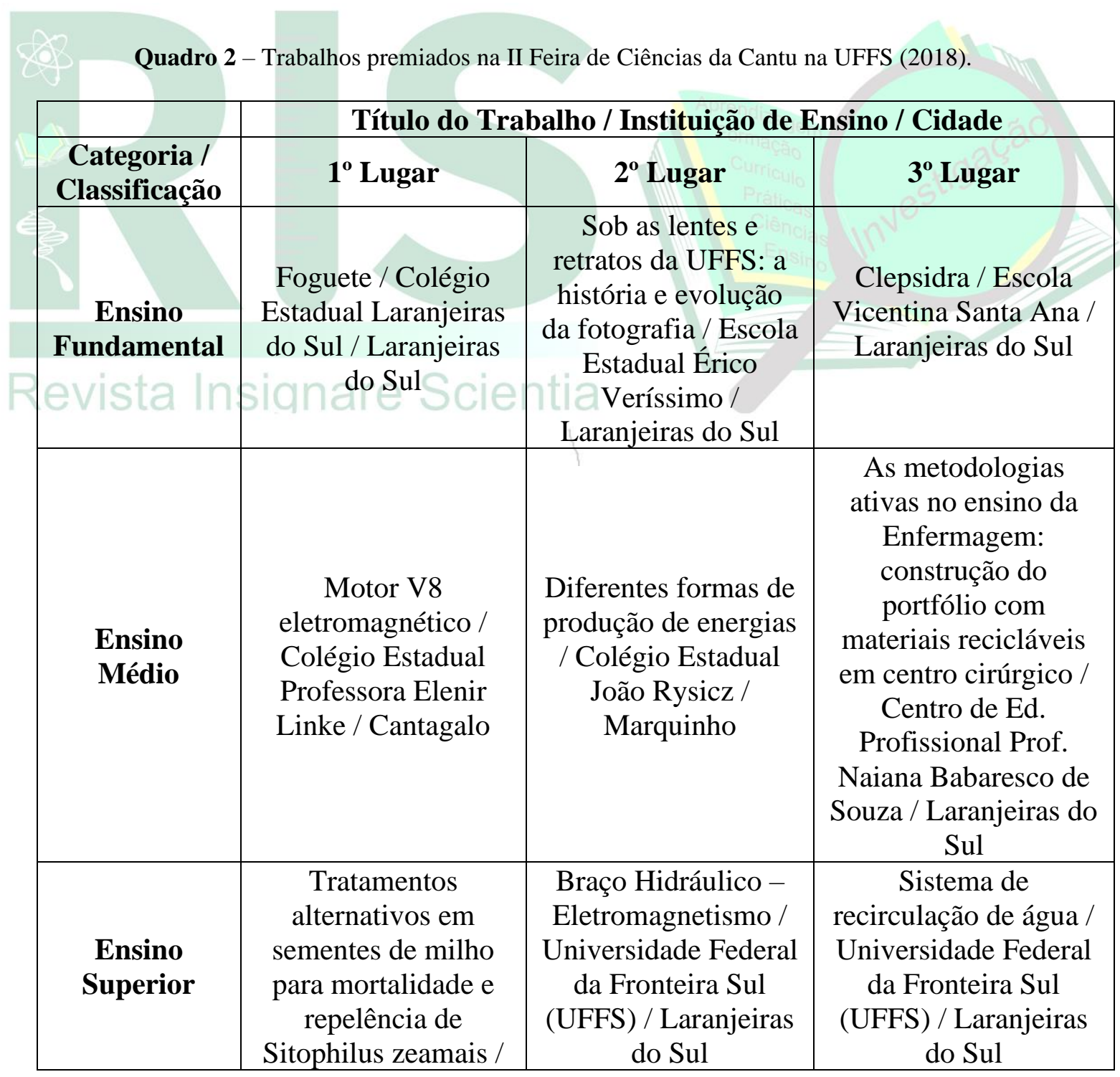




\begin{tabular}{|c|c|c|}
\hline & $\begin{array}{c}\text { Universidade Federal } \\
\text { da Fronteira Sul } \\
\text { (UFFS) / Laranjeiras } \\
\text { do Sul }\end{array}$ & \\
\hline $\begin{array}{c}\text { Trabalho } \\
\text { Destaque }\end{array}$ & Motor com Pistão Eletromagnético / Colégio Estadual Ludovica \\
Safraider / Rio Bonito do Iguaçu
\end{tabular}

No quadro 2 observa-se que, na segunda edição da Feira de Ciências da Cantu na UFFS, realizada em 2018, foram premiados trabalhos de 8 instituições de ensino localizadas em quatro cidades. Os trabalhos abrangiam as áreas de Ciências Agrárias, Natureza, Humanas, da Saúde, Sociais, Engenharias e Artes, o que demonstra que a Feira de 2018 teve um alcance maior no que se refere a áreas do conhecimento, se comparada com os trabalhos premiados de 2017, o que também pode ser constado pela análise da figura 6. Os trabalhos de Física ainda são os que predominam sobre os demais.

Quadro 3 - Trabalhos premiados na III Feira de Ciências da Cantu na UFFS (2019).

\begin{tabular}{|c|c|c|c|}
\hline & \multicolumn{3}{|c|}{ Título do Trabalho / Instituição de Ensino / Cidade } \\
\hline $\begin{array}{l}\text { Categoria / } \\
\text { Classificação }\end{array}$ & $1^{\circ}$ Lugar & $2^{\circ}$ Lugar & $3^{\circ}$ Lugar \\
\hline $\begin{array}{c}\text { Ensino } \\
\text { Fundamental }\end{array}$ & $\begin{array}{c}\text { Dessalinização / } \\
\text { Colégio Estadual } \\
\text { Ludovica Safraider / } \\
\text { Rio Bonito do Iguaçu }\end{array}$ & $\begin{array}{l}\text { Energia sustentável / } \\
\text { Colégio Estadual } \\
\text { General Eurico } \\
\text { Gaspar Dutra / } \\
\text { Virmond }\end{array}$ & $\begin{array}{c}\text { Funcionamento do } \\
\text { motor de combustão / } \\
\text { Colégio Estadual do } \\
\text { Campo Ireno Alves dos } \\
\text { Santos / Rio Bonito do } \\
\text { Iguaçu }\end{array}$ \\
\hline $\begin{array}{l}\text { Ensino } \\
\text { Médio }\end{array}$ & $\begin{array}{c}\text { Na Divisa do Amor - } \\
\text { A Guerra Fria e o } \\
\text { Muro de Berlim / } \\
\text { Instituto Federal do } \\
\text { Paraná (IFPR) / } \\
\text { Coronel Vivida } \\
\end{array}$ & $\begin{array}{c}\text { ROBOLIX - A } \\
\text { lixeira interativa / } \\
\text { Colégio Estadual } \\
\text { Professora Izabel } \\
\text { Fonseca Siqueira / } \\
\text { Reserva do Iguaçu } \\
\end{array}$ & $\begin{array}{c}\text { Usina Geotérmica/ } \\
\text { Colégio Estadual } \\
\text { Professor Gildo Aluísio } \\
\text { Schuck / Laranjeiras do } \\
\text { Sul }\end{array}$ \\
\hline $\begin{array}{l}\text { Ensino } \\
\text { Superior }\end{array}$ & $\begin{array}{c}\text { Erva Mate: } \\
\text { Ultrapassando } \\
\text { Fronteiras / } \\
\text { Universidade Federal } \\
\text { da Fronteira Sul } \\
\text { (UFFS) / Laranjeiras } \\
\text { do Sul }\end{array}$ & $\begin{array}{l}\text { Bandejas expandidas } \\
\text { biodegradáveis / } \\
\text { Universidade } \\
\text { Federal da Fronteira } \\
\text { Sul (UFFS) / } \\
\text { Laranjeiras do Sul }\end{array}$ & $\begin{array}{c}\text { ECOAQUA / } \\
\text { Universidade Federal } \\
\text { da Fronteira Sul } \\
\text { (UFFS) / Laranjeiras do } \\
\text { Sul }\end{array}$ \\
\hline $\begin{array}{l}\text { Trabalho } \\
\text { Destaque }\end{array}$ & $\begin{array}{c}\text { ECOAQUA / } \\
\text { Universidade Federal } \\
\text { da Fronteira Sul } \\
\text { (UFFS) / Laranjeiras }\end{array}$ & $\begin{array}{c}\text { Alternativa } \\
\text { sustentável para o } \\
\text { tratamento de esgoto } \\
\text { residencial / Centro }\end{array}$ & $\begin{array}{l}\text { Energia sustentável / } \\
\text { Colégio Estadual } \\
\text { General Eurico Gaspar } \\
\text { Dutra / Virmond }\end{array}$ \\
\hline
\end{tabular}




\begin{tabular}{|l|c|c|c|}
\hline do Sul & de Educação \\
& Profissional Prof. \\
& Naiana Babaresco de \\
Souza / Laranjeiras & do Sul & \\
\hline
\end{tabular}

O quadro 3 revela que, em 2019, os trabalhos premiados tinham foco nas áreas de Engenharias, Ciências Agrárias, da Natureza, Sociais Aplicadas e Humanas, os quais foram submetidos por equipes de 8 instituições de ensino, situadas em cinco municípios.

Ressalta-se que, na terceira edição da Feira, realizada em 2019, foram premiados três trabalhos destaque (classificados em $1^{\circ}, 2^{\circ}$ e $3^{\circ}$ lugar). Na ocasião um trabalho premiado na categoria Ensino Fundamental e outro na categoria Ensino Superior também foram premiados como destaques do evento, corroborando com a avaliação da banca examinadora que já tinha seus próprios critérios para análise dos trabalhos. Vale lembrar que os trabalhos destaque foram escolhidos mediante voto popular.

Conforme observado nos quadros 1,2 e 3 , a diversidade dos trabalhos premiados sinaliza que a Feira de Ciências da Cantu na UFFS valoriza e oportuniza diferentes formas de trabalhos e áreas do conhecimento, promovendo a interação entre as áreas e possibilitando o compartilhamento de conhecimentos e experiências entre os participantes. De fato, o termo "Ciências" no nome do evento foi assumido enquanto conhecimento que abrange todos os campos do saber. Este termo pode ser entendido no seu sentido mais amplo, referindo-se muito mais à pesquisa/divulgação científica em qualquer ciência ou área do conhecimento (GUIDOTTI; ARAUJO, 2020).

\section{CONSIDERAÇÕES FINAIS}

Este trabalho buscou descrever a Feira de Ciências da Cantu na UFFS enquanto possível mecanismo para a divulgação de projetos, trabalhos e conhecimentos. O evento desempenha um papel relevante na educação científica de alunos, professores, técnicos, especialistas e visitantes, aproveita o potencial criativo e produtivo de estudantes, valoriza o professor como orientador e integra comunidades. A realização deste tipo de evento atende os objetivos e finalidades institucionais, contribuindo com o 
estreitamento e consolidação do relacionamento da instituição com a comunidade, promovendo o reconhecimento e fortalecimento da imagem institucional.

As três edições da Feira de Ciências da Cantu na UFFS oportunizaram conhecer trabalhos acadêmicos e experimentos pedagógicos dos mais variados temas. Muitos destes temas se referem a estudos da realidade dos educandos, da cidade ou do campo, o que também confirma uma tendência de ampliação das feiras de ciências para incorporar atividades realizadas em outros componentes curriculares que não apenas os da área de Ciências da Natureza. Além do mais, a Feira contribui de forma significativa na construção de conhecimento, possibilitando que os estudantes investiguem e apresentem soluções e novas tecnologias nas mais diversas áreas. Isso mostra que as feiras de ciências exercem importantes momentos formativos para seus participantes, proporcionando a construção de conhecimentos contextualizados para além de um currículo engessado, indo ao encontro dos interesses dos participantes envolvidos, que buscam novos conhecimentos ao investigarem situações-problema e soluções para estes, como também ao desenvolverem novas produções que podem trazer benefícios para a sociedade. Verifica-se, ainda, que a contextualização pode acontecer com um trabalho interdisciplinar de modo que conceitos e linguagens de diferentes componentes curriculares sejam relacionados, num contexto histórico, social ou ambiental.

Os eventos de mostra científica vêm aumentando pelo país, sendo que a necessidade de transitar entre diferentes públicos oportuniza ao estudante o desenvolvimento de um repertório expandido dos seus argumentos, além da divulgação de seu projeto para mostrar sua aplicabilidade, relevância e comprometimento social. Mesmo sem políticas públicas decisivas de apoio às feiras de ciências, elas se multiplicam, numa revolução pedagógica constante, vindo ao encontro do desejo por uma educação mais qualificada que proporcione aprendizagem efetiva.

Dessa forma, as feiras de ciências extrapolam o objetivo de exposição dos trabalhos a diferentes públicos e adquirem um aspecto formativo a todos os envolvidos: é possível pensar em momentos de divulgação científica (entre os pesquisadores e visitantes ou pesquisadores envolvidos em outros projetos), compartilhamento de conhecimento e experiências e também de nível adequado de comunicação científica. Essa habilidade é apreciada nas práticas de letramento acadêmico e educação/formação 
científica, que são influentes no contexto escolar e universitário, considerando os processos de ensino, aprendizagem e socialização do conhecimento. Ao participarem da Feira de Ciências da Cantu na UFFS, os apresentadores de trabalhos, ao realizarem trocas interculturais com o público e com outros estudantes, professores e especialistas, podem construir novas concepções sobre o conhecimento de várias disciplinas, lhes permitindo um olhar mais integrado e menos fragmentado do mundo, além de desenvolver outras habilidades importantes como a expressão oral de um determinado conhecimento.

A Feira de Ciências da Cantu na UFFS sediada no Campus Laranjeiras do Sul, um espaço aberto ao público regional, configurou-se como um evento interdisciplinar que envolveu a atuação dos apresentadores de trabalhos de modo a favorecer a construção do conhecimento científico, o pensamento crítico e sua autonomia. Além disso, o evento propiciou a participação da sociedade em geral, evidenciando sua importância na popularização da ciência através da grande interação entre os alunos e professores das escolas, alunos, professores e técnicos da UFFS e comunidade externa do Território Cantuquiriguaçu. Os dados referentes às participações nas três edições do evento revelam a evolução do engajamento da comunidade acadêmica da UFFS e demais instituições participantes e do público em geral nas três edições do evento. Adicionalmente, o evento proporcionou uma ampla divulgação da UFFS, dos cursos de Graduação da Universidade e uma excelente oportunidade de divulgação científica dos trabalhos realizados pela comunidade escolar e acadêmica, estreitando os laços do ensino, pesquisa e extensão, que são os pilares básicos da Universidade. 


\section{REFERÊNCIAS}

BRASIL, Ministério da Educação. Secretaria de Educação Básica. Programa Nacional de Apoio às Feiras de Ciências da Educação Básica: Fenaceb. Brasília, DF: MEC: Secretaria de Educação $\quad$ Básica, $2006 . \quad$ Disponível em: http://portal.mec.gov.br/seb/arquivos/pdf/EnsMed/fenaceb.pdf. Acesso em: 16 dez. 2020.

GALLON, M. et al. Feiras de Ciências: uma possibilidade à divulgação e comunicação científica no contexto da educação básica. Revista Insignare Scientia, Chapecó, SC, v. 2, n. 4, p. 180-197, set./dez.2019. DOI: https://doi.org/10.36661/2595-4520.2019v2i4.11000. Disponível em: https://periodicos.uffs.edu.br/index.php/RIS/article/view/11000/7339. Acesso em: 16 dez. 2020.

GAUTERIO, P. C.; GUIDOTTI, L. S.; ARAÚJO, R. R. Feira de Ciências: Espaço de interação e investigação na formação continuada de professores. In: ENCONTRO NACIONAL DE PESQUISA EM EDUCAÇÃO EM CIÊNCIAS, 11., 2017, Florianópolis. Anais eletrônicos [...]. Florianópolis, SC: UFSC, 2017. Disponível em: http://www.abrapecnet.org.br/enpec/xienpec/anais/lista_area_04.htm. Acesso em: 16 dez. 2020.

GUIDOTTI, C. S.; DE ARAUJO, R. R. Mostras de Ciências na Escola: aspectos teóricopráticos da pesquisa em sala de aula. Revista Insignare Scientia - RIS, Chapecó, SC, v. 3, n. 3, p. 46-63, 13 nov. 2020. DOI: https://doi.org/10.36661/2595-4520.2020v3i3.11777. Disponível em: https://periodicos.uffs.edu.br/index.php/RIS/article/view/11777. Acesso em: 09 mar. 2021.

SANTOS, A. B. Feiras de Ciência: um incentivo para desenvolvimento da cultura científica. Revista Ciência em Extensão, São Paulo, v.8, n.2, p.155-166, 2012. Disponível em: https://ojs.unesp.br/index.php/revista_proex/article/view/717/677. Acesso em: 16 dez. 2020.

SOUSA, V. P. et al. Feiras de Ciências como espaços de divulgação científica: contribuições da IV Feira Municipal de Ciência e Tecnologia de Campos dos Goytacazes - RJ. In: SIMPÓSIO NACIONAL DE ENSINO DE CIÊNCIA E TECNOLOGIA, 5.; SEMANA ACADÊMICA DA LICENCIATURA INTERDISCIPLINAR EM CIÊNCIAS NATURAIS, 2., 2016, Ponta Grossa. Anais eletrônicos [...]. Ponta Grossa, PR: UTFPR, 2016. Disponível em: http://www.sinect.com.br/2016/selecionados.php. Acesso em: 16 dez. 2020.

TREVISOL, J. V.; CORDEIRO, M. H.; HASS, M. (orgs). Construindo agendas e definindo rumos: I Conferência de Ensino, pesquisa e extensão da UFFS. Chapecó, SC: UFFS, 2011. (Memórias UFFS; v. 1).

UNIVERSIDADE FEDERAL DA FRONTEIRA SUL. Conselho Universitário. Resolução no 31/CONSUNI/UFFS/2015. Aprova adequações ao novo Estatuto da Universidade Federal da Fronteira Sul. Chapecó, SC: UFFS, 2015. Disponível em: https://www.uffs.edu.br/atosnormativos/resolucao/consuni/2015-0031. Acesso em: 16 dez. 2020.

UNIVERSIDADE FEDERAL DA FRONTEIRA SUL. Conselho Universitário. Resolução no 3/CONSUNI/UFFS/2016. Aprova o Regimento Geral da Universidade Federal da Fronteira Sul. Chapecó, SC: UFFS, 2016. Disponível em:https://www.uffs.edu.br/atosnormativos/resolucao/consuni/2016-0003. Acesso em: 16 dez. 2020. 